Thinking Globally, Working Locally: Employability and Internationalisation at Home

Date of submission: 2 September 2016

Date of revision: 29 August 2017

Word count (including notes and references): 6289 


\begin{abstract}
As an approach to the internationalisation of higher education, Internationalisation at Home (IaH) looks beyond the mobility of a minority of students, emphasizing instead the delivery to all students of an internationally-focussed curriculum, and the embedding of intercultural communication. This can be expanded to include extra-curricular activities and building relationships with local cultural and ethnic community groups. The MA in International Development at Nottingham Trent University UK has implemented this approach, looking beyond both mobility and curriculum to apply IaH directly to student employability, embracing intercultural competence as a key professional skill. This paper explores the efficacy of this combination in the MA's Professional Development Pathway, which requires students to complete a placement which demonstrates international and intercultural engagement, usually undertaken "at home", and to critically reflect not just on their professional skills, but on their ability to engage in the ethical practice which is a key element of IaH.
\end{abstract}

(150 words)

\title{
Keywords
}

Internationalisation at Home; International Development; employability; intercultural competence; pedagogy. 


\section{Thinking Globally, Working Locally: Employability and Internationalisation at Home}

\section{Introduction: Internationalisation at Home and the extended curriculum}

Internationalisation at Home $(\mathrm{IaH})$ is an approach to the internationalisation of Higher Education which looks beyond the mobility of a minority of students, emphasizing instead the delivery to all students of an internationally-focussed curriculum and the embedding of intercultural communication in culturally diverse settings (Wächter, 2003). However, it is a broad term, which requires contextualising in order to be made concrete and meaningful, and has been implemented in regionally distinct ways across the UK, Northern Europe, Australia, Canada and the US. Nilsson (2003:31) defines IaH simply as 'any internationally-related activity with the exception of outbound student mobility', but qualifies this by outlining an approach, like Wächter's, which combines academic knowledge with fostering an attitude of openness: 'they should have open minds and generosity towards other people; know how to behave in other cultures and how to communicate with people with different religions, values and customs, and not be scared of coping with new and unfamiliar issues' (2003:39). Other approaches to IaH, for example from EP-NUFFIC, the Netherlands Universities' Foundation for International Co-operation (2014:2) are more skill-based, focused on providing students with a combination of 'international competencies' (those relevant to interaction with people from other countries) and 'intercultural competencies', defined as 'social skills and forms of behaviour relevant to interaction with people from other cultures' (cited from de Wit, 2010).

The first priority of IaH was embedding intercultural competence into an internationalised curriculum. However, Killick (2007:36) identified that it could equally benefit from application in practice as part of an "extended curriculum" including volunteering and global 
citizen awards, while Knight (2008:13) noted that the "at home" concept gives greater prominence to the use of 'extra-curricular activities, relationships with local cultural and ethnic community groups, as well as the integration of foreign students and scholars into campus life and activities.' This is reflected in Beelen and Jones' (2015:69) definition of IaH as the "purposeful integration of international and intercultural dimensions into the formal and informal curriculum for all students within domestic learning environments', and the Higher Education Academy's (2014) recommendation that internationalised programmes should make an effort to 'Build in experiential learning so that students can experience and reflect on the intercultural aspects of their learning alongside the core disciplinary learning' $(2014: 3)^{1}$. This experiential and "beyond the classroom" approach is also, we argue, perhaps more appropriate for developing the affective dimension which Barker and Mak (2013) and Jones (2016) stress is an important part of developing intercultural competence: the need for students to build confidence by learning to adapt to encounters beyond their comfort zone, by being confronted with 'disorienting dilemmas' (Mezirow, 1991, cited in Jones, 2016:110) associated with communicating across potential barriers of not just nationality and culture, but race, gender, class or other forms of power.

Knight (2008:14) notes that one way of achieving this is the 'Involvement of students in local cultural and ethnic organisations through internships, placements and applied research'. A link between employability and internationalisation seems clear: Beelen (2011) has identified that the most important rationale for internationalisation in HEIs is to enhance student "preparedness" for a globalized world, while in Lambert and Usher's (2013) survey of 1400 domestic Canadian students, almost $90 \%$ felt that international skills, including

\footnotetext{
${ }^{1}$ See also Braskamp (2009:2-3) on the importance of curriculum, "co-curriculum" (related activities outside of the classroom) and "community" (building relationships with communities external to the University).
} 
'being able to work in an unfamiliar environment or culture' would be 'at least somewhat important for finding a job after University' (Lambert and Usher, 2013:17). The British Council (2013) and Think Global (2011), also, have published research on the importance of intercultural skills to employers, and on the gap between employers' need for globallyprepared recruits, and the capacities of current UK school-leavers and graduates. The Erasmus Impact Study (European Commission, 2014:14) finds that 92\% of employers surveyed were looking for "transversal skills" including openness and curiosity, confidence, and tolerance towards other values and behaviours, and that study abroad helped $81 \%$ of Erasmus students to improve these skills. Killick (2017:43), most recently, has emphasized the importance to global graduates of "cultural dexterity" - the ability to be sensitive to the culture of others, without imposing one's own.

However, as Barker and Mak (2013) argue, there is little agreement on how to 'link the global classroom to the global workplace' (citing Ramburuth and Welch, 2005:6) except through periods of 'cultural immersion' via overseas internships (Ramburuth and Welch, 2005:11-12) - an experience which will only ever be confined to a minority of students. From an IaH perspective, Van Gaalen and Gielesen $(2014 ; 2016)$ argue that internationally and interculturally competent graduates can best be achieved 'if institutions consciously create controlled situations that lead to intercultural collaboration and the utilization of students' specific international knowledge' (2014:16), while EP-NUFFIC (2014b) identify that work placements at international organisations in the home country have 'high potential' for delivering internationalised professional and personal skills and knowledge, although they are 'still not much applied' (2014b:2). Jones (2013; 2016) has made a strong case for asking whether IaH (or 'local internationalization') can enhance the employability of non-mobile students, arguing that 'it is clear that domestic environments could play an equivalent role in 
offering opportunities for experiential learning in an intercultural context, taking people beyond their comfort zones' (Jones, 2013:101). Hard evidence of a link, however, has been 'limited or non-existent' and 'we have yet to make the most of the diversity in our ... local communities to support intercultural learning in domestic settings' (Jones, 2016:114). Soria and Troisi (2014) have begun to address this in the US context with some early findings which suggest that IaH programmes may yield greater benefits than study abroad in terms of acquiring global, international and intercultural competencies. This paper therefore adds to this emerging literature by outlining a practical application of IaH which embraces intercultural competence acquired domestically as a key employability skill.

\section{Limitations of this study}

Focussing on the Professional Development Pathway (PDP) of the MA in International Development (MAID) at Nottingham Trent University, this is by nature a small-scale study undertaken within a single institution. It takes IaH to mean experiences based in the home country of the institution, and therefore draws on empirical reflections relating to placements undertaken at domestic UK organisations with an international dimension. Although these can occasionally develop into opportunities for foreign travel (see Students B and K, on pp. 13 and 14 respectively), it is the experiences gained in the home country of the institution which are our current focus. The reflections are taken from 12 sample portfolios from two years of the MA programme (completing 2015 and 2016), seven by domestic students and five international, supplemented by two interviews with placement providers. The sample is therefore clearly quantitatively limited, and comes with two further caveats.

The first is that International Development students might be expected to have a positive bias towards an internationalised experience, exemplifying a natural convergence between 
the roles of what Harrison (2016, unpublished) has termed the professional global worker, and engaged global activist-citizen. While this may be the case, we offer this tentatively as a potential framework for integrating IaH into other domestically-taught disciplines through internationalised learning outcomes, experiential work-based elements, and assessment requirements. The second is that international students, who make up approximately half of the cohort of 12-15 students each year, will bring their own experiences of adapting to new environments, languages and cultural values. Their facility for intercultural competence, or "cultural capital", should not however be assumed. Gribble (2015:8), for example, has made a strong case in the Australian context for using work placements to enhance international students' own "portability", giving them 'a "kit bag of skills" that will enable them to succeed in a borderless world', and clearly this merits further study. While the backgrounds of the students here therefore are identified for analytical clarity, the distinctions between the experiences of the intercultural workplace for students from different cultural backgrounds are not the primary focus. This paper rather considers the extent to which an IaH framework helps students across both domestic and international groups to develop across multiple dimensions: applying theoretical knowledge to concrete issues via a problem-solving approach; demonstrating more mainstream employability or professional skills; and developing intercultural competence - increased confidence in their intercultural communication skills, and an ability to engage with diverse communities.

This data is therefore presented with some caution, but reflects the beginning of a process to evaluate the effectiveness of an IaH approach in creating Killick's "global graduates" (2017: 38) without the need for mobility, and allows us to explore a novel approach to integrating internationalised learning outcomes, delivery and assessment into professional development provision, about which little has so far been published. More broadly, the paper 
also highlights some of the issues raised by bringing together the neoliberal discourse of employability outcomes with the social responsibility discourse of Internationalisation at Home (see Killick, 2017:57), which should help to inform educators looking to universalise IaH across disciplines.

\section{The MAID Professional Development Pathway: meeting internationalised outcomes}

The MA in International Development has been running at Nottingham Trent University since 2012, and has incorporated from the beginning a Professional Development block, worth 20 credits of an 80 credit module on International Development. ${ }^{2}$ This is in line with the strategic objectives of an educational institution which prioritises delivering both a global outlook and enhanced employability for its students, alongside the delivery of the curriculum. Since 2015, the University has adopted a new set of strategic objectives, which include 'Creating Opportunity' (through innovative collaborations with employers), 'Enriching Society' (aligning expertise with a wide range of strategic partner institutions), and ‘Connecting Globally’ (nurturing global citizenship and an international research community). ${ }^{3}$ This strategic focus on employability, social engagement, and global orientation lends itself to an internationalised agenda; however, with a strong emphasis on building relationships with local and regional bodies and employers, and with a significant number of students still recruited domestically, internationalisation with an "at home" orientation is particularly appropriate.

\footnotetext{
${ }^{2}$ The MA programme overall consists of 180 credits, including a 40 credit research module, and a 60 credit dissertation. The PDP block was initially optional but recommended, but is now compulsory to ensure student engagement with preparing to work in international development.

${ }^{3}$ NTU Strategy, Creating the University of the Future, https://www.ntu.ac.uk/strategy/ (accessed 15 May 2017).
} 
While the classroom element of the MAID therefore covers global economic systems and governance, global-local connections, theories of development, risk and resilience, these are presented within a framework of learning outcomes which bring together three key strands of an internationalised agenda: academic learning, professional competence and appropriate ethical behaviours. The learning outcomes include: evaluating personal development in relation to skills and knowledge gained throughout the programme; providing a critical and reflexive understanding of the complex and multi-disciplinary skills necessary to work competently in the international development sector; identifying and managing complexity and change in the international development field using a range of problem solving approaches; engaging intellectually, behaviourally and effectively with groups and individuals from a wide range of backgrounds and cultures, and working effectively in a complex and changing professional environment. These are assessed at multiple points by scrutiny of traditional intellectual and academic skills (annotated bibliography, essay, case study). However, this is then supplemented by the submission of a PDP Portfolio which assesses students' ability to develop and critically reflect upon the skills and attitudes necessary to respond to the challenging issues International Development poses, and to apply the knowledge attained from theoretical part of the programme in the professional world. The process of developing this understanding "at home", without the necessity for international travel, is supported in three ways: in the classroom, through self-directed learning, and through a placement.

The classroom element consists of a short series of seminars, interspersed throughout the year, covering the process of becoming a reflexive practitioner (drawing on Kolb, 1984); developing professional skills in key areas (including communication skills, team working, management of change, leadership, project management and problem solving); developing 
detailed personal goals (drawing on Drucker, 1954 and Doran, 1981), and working with values across cultures (drawing on Schwartz, 2012). Between seminars, students complete a series of self-directed e-Portfolio exercises on the portal which provide reflective activities which support the development of the key transferrable professional skills. The most significant challenge for students is the requirement to complete a 100-hour placement, usually (but not exclusively) undertaken in the UK. ${ }^{4}$ While there is perhaps a paradox in running a postgraduate course in International Development in which travel abroad is not an essential element, students are tasked with undertaking volunteering or paid work at any organisation or company whose work deals with social, economic or environmental development with an international dimension. This is a largely independent initiative; the Placement Supervisor will help to identify and contact suitable organisations if needed, however the students' ability to find and negotiate their own placement is considered to be part of professional skills development.

The PDP block, consisting as it does largely of experiential learning, is then assessed by the submission of a reflective multi-part portfolio, consisting of: (i) a Personal Development Plan which puts the placement into the context of their broader professional and personal development; (ii) a placement report with evaluative element, which shows an ability to evaluate the host organisation, the application of theoretical and underpinning knowledge to the placement experience, and a discussion and evaluation of professional skills development; and (iii) supporting evidence which documents the activities and development undertaken during the placement. There has been interesting work done on ways of assessing students' acquisition of intercultural capability - for example, Hammer (2009) on the 'Intercultural

\footnotetext{
${ }^{4}$ International students have also occasionally completed their placements "at home", in their country of origin, although most find providers in the UK.
} 
Development Continuum' and the shift towards an adaptive mindset, Spencer-Oatey and Stadler (2009) on competency clusters which combine problem-solving abilities, communication, relationship-building and attitudes, and Deardorff (2006:256) on the 'process model' which explores how shifts in attitude and knowledge are translated into internal outcomes (greater adaptability) and external outcomes (effective use of appropriate communication and behaviour). The MAID PDP assessment strategy integrates elements of these, but as part of a broader approach which assesses application of knowledge, professional skills and attitudes, and intercultural capability. This is focussed on the learning outcomes listed above, but with the emphasis on reflective ability, an understanding of the multi-disciplinary skills needed to work in international development, productive engagement with groups and individuals from a wide range of backgrounds and cultures, and recognising responsibility as a local, national and international citizen.

The PDP therefore uses an IaH framework to deliver the University's key strategic objectives of social engagement, employability, and global connectedness in the following ways: (i) embedding intercultural communication into practical experience, encouraging students to apply their academic knowledge (Wächter, 2003); (ii) enhancing student "preparedness" for a globalized professional environment - identified as the most important rationale for internationalisation in HEIs (Beelen, 2011); (ii) encouraging the building of relationships between students and local cultural and ethnic community groups (Knight, 2008), which supports the development of attitudes of openness to multiple perspectives, and exposes students to the ethical dimensions of international development practice. The following section evaluates this delivery, drawing on students' own reflections on their learning, and on semi-structured interviews with two key placement providers. 


\section{Professional Development beyond the comfort zone: evaluation and discussion}

Finding domestic placement providers which are logistically feasible, willing, and suitable for facilitating international and intercultural learning is not a simple process; however, students in recent years have completed successful placements at a number of UK-based organisations, both in the East Midlands and nearer to their home towns, which engage in humanitarian support, cross-cultural development, or sustainable development. These organisations have included the Borderlands Refugee Centre in Bristol; Global Justice Nottingham (a trade and environmental justice advocacy group); Muslim Charity Helping the Needy (organising poverty alleviation and participatory development programmes); Marches Energy Agency (addressing fuel poverty and helping communities transition to low-carbon energy); Nottingham and Nottinghamshire Refugee Forum; Oxfam Nottingham; the Sudanese Community School in Nottingham; a Language Buddies programme for school students with English as a second language; and Transition Town Totnes (focussed on strengthening the local economy and transitioning to a low-energy future).

From their reflections on these experiences, there is no lack of evidence that students make full use of the opportunity both to apply their academic knowledge - to get outside of the 'academic bubble' (Provider Y) - and to develop their professional skills in the form of problem-solving, teamwork, communication and leadership. One student, for example, who was later offered a position as a project manager with the provider, commented:

I applied my theoretical skills learnt at University, for instance ... informing people about renewable sources such as solar panels and food/water security ... it was a wonderful experience to share my knowledge about climate change with a wider audience. (Student A, 2015). 
Another, who had worked for a home-based organisation supporting participatory development projects in Pakistan, was quick to identify that much of what they had learned took the form of transferrable professional skills which were highly relevant to their own career development:

These skills ... can be applied in almost any profession, but they are specifically relevant to my own career development as they support my Personal Development Plan and were directly relevant to the International Development field. (Student B, 2015).

All students, in fact, have tended to place emphasis on developing their knowledge and acquiring transferrable professional skills, which is perhaps unsurprising in a pathway with a strong focus on employability. To a certain extent, placement providers have shared this instrumental focus on receiving knowledge and labour in return for professional skills development. One provider described this as 'a two-way thing' in which the labour of the students is repaid through the provision of training in areas such as safeguarding, first aid and confidentiality. These are described as 'transferrable to basically any job that they might do ... and I think the students that have been on placement have grabbed the opportunity ... to improve themselves professionally.' (Provider X, 2016).

In addition, however, most student portfolios, and certainly the most reflective in quality, highlight the experience of being placed in an inter-cultural environment, and on the challenges this presents to their communication skills and cultural assumptions. There are particular references to being pushed out of their comfort zone (see Barker and Mak, 2013, above), building confidence when dealing with unfamiliar situations, developing communicative ability, and developing a more open mindset (as per Hammer, 2009, above). 
One speaks of becoming aware that she is 'nervous' of her lack of language skills when dealing with non-native English speakers, and resorting to taking on tasks 'where I had less contact with people.' By the end of her placement, however, she is speaking of the provider's clients as 'friends':

some members they would talk about their experiences ranging from their journey to the U.K and their experiences on arrival here. Although I never directly asked, as I did not want to appear insensitive or pry, as we became more familiar with one another we spoke easily. (Student J, 2016).

Another, who ran the NTU Global Society, including the organisation of a successful trip to the Conference of Youth 2015 in Paris, finds that she 'became more confident in my leadership abilities' and 'a more confident person both at work and at home' as a result of taking on the additional responsibilities and challenges this entailed (Student K, 2016).

For international students working in UK organisations, the experience of having already crossed borders, languages, cultures and institutions appeared to give them a particular understanding of both linguistic and cultural translation issues, described by one provider as an awareness that 'not everything goes smoothly when it comes to communication ... just like they as somebody who came from a different place, understanding how life in the UK works ... they've brought that experience with them' (Provider X, 2016). This appears to support the case both for the value to employers of intercultural competence, and for the value of study abroad - both outbound and inbound in acquiring it (see European Commission, 2014, op. cit.). However, even here, there was evidence that placements specifically further enhanced students' openness to working across cultural difference and enhanced confidence. One states that 'this has allowed me 
to improve my skills in communication and has opened my mind to accepting differences in cultures and societies,' (Student D, 2016). A second, in spite of feeling that she had already had 'the advantage of living in different cultures and societies', spoke of growing in confidence when overcoming cultural barriers:

When I first received the application form for the programme I was afraid of taking part due to the concerns about my accent and possible language barriers. However, ... Since this experience, I am no longer afraid to push myself further and take greater steps to learn without shying away from new challenges. (Student E, 2016)

For one, this intercultural learning also extended beyond language and communication to challenge ideas about cultural norms and gender roles, as she found when asked during her placement to take on the role of 'experienced advisor' and train new recruits:

It was a bit new and difficult at the beginning ... because I am from a cultural background where girls are trained to respect male figures ... After my session with the first trainee I got more confidence in the leadership role and I hope to continue to build more on the skill, as I have opted to continue working with the organisation. (Student C, 2015).

One of the key findings of a survey of the portfolios, however, is that the main elements of $\mathrm{IaH}$, whether more instrumental (the application of specific knowledge, and the development of professional skills) or more ethical (the intercultural values and attitudes needed to make the judgements on development issues), are often (if not always) inextricable in students' reflections. One student, for example, valued the training sessions provided because they 'have imbued me with essential knowledge that supports my masters course as well as 
equipped [me] with the appropriate skills and behaviour in humanitarian support' and 'not only strengthen[ed] my skills in communication, public speaking, time management and problem solving, but also develop[ed] them to a higher level in a multicultural context' (Student F, 2016). A second student expressed a similar view, that gaining new knowledge, improving their own potential employability, and developing their understanding of the experiences of others, were implicitly connected; training they received into people trafficking from the Red Cross 'allowed me a better insight into the lives of those seeking asylum, and also provided a new area of interest for me, and a possible avenue to direct my career' (Student G, 2016). An international student, meanwhile, who split their 100-hour placement across two providers, explicitly valued the combination of more professional skills, and an ethical understanding of the importance of advocacy, which they gained from this experience. While one placement had introduced them to 'the business side of the NGO world', supporting the 'managerial, customer service, and leadership skills relevant to my personal and career life', the second had provided a very different perspective on human agency. Having become increasingly aware of the 'man-made' nature of poverty and inequality, they reflected that:

[Placement 2] introduced me into the world of practical activism, taught me not to be afraid in voicing my opinions, and this has been a great addition to my personal and professional development. (Student H, 2016).

There is evidence here that cross-cultural capability cannot be reduced to ease of transition between different cultural groups, but requires more active engagement, supporting Barker and Mak's (2013) argument that intercultural competence may require not just “openness", but speaking up, becoming 'not afraid to voice [their] opinions' (Provider Y), challenging opinions based on multiple hierarchies of ethnicity, race, gender, class, and citizen status. 
Domestic students can face specific challenges in this area, particularly in the face of an increasingly prevalent anti-migrant political discourse. Student J, working in a Refugee Centre in her home city, reflects on learning to 'speak up' for her clients when negotiating with 'others are not from our own organisation and have little experience dealing with refugees', supporting their right not to be filmed, for example, 'as I did not think they would be comfortable with this.' (Student J, 2016). This included having to negotiate negative attitudes expressed in her own ethnically white community towards refugees. ${ }^{5}$ According to the provider:

Of all of our interns, she's the only one who's come from the local community, and that's ... given us a real insight ... there's definitely a dynamic there, she is an advocate for us among the local community that she is part of, and we are very lucky to have someone who speaks up for us as passionately as she does. (Provider Y, 2016).

While they value students' skills - organisation, teamwork, communication skills, problemsolving, budgeting, and even more basic practical skills such as food hygiene and customer experience - our findings suggest that providers place an additional emphasis on attitudes and engagement, developing those who are 'willing to listen, and I think willing to have their views challenged, so they're flexible, where they've really been surprised by things and changed their views because of it' (Provider Y). Using an IaH framework for the PDP, and specifically the placement element, does therefore appear to provide an opportunity for students to develop and make connections between internationalised knowledge, skills and attitudes. However, there are some differences in emphasis in students' reflections which

\footnotetext{
${ }^{5}$ The ethnic breakdown of the domestic MAID students varies from year to year, though it is broadly $75 \%$ ethnically white. This should not have significant impact on the implementation of IaH, but it may inform those students' reflections on their intercultural experiences, and would be worthy of further study.
} 
raise questions over how effective this approach is at delivering the ethical and intercultural dimension of internationalisation.

As both Killick (2013; 2017:57) and Pashby and Andreotti (2016) have cautioned, there are some contradictions in trying to deliver an approach to internationalisation which combines the development of employable global professionals ready for a marketised world, with open, thoughtful, sustainable and intercultural development practitioners, and thus focusing simultaneously on 'two dimensions of being, identity and agency' (Killick, 2013: 722). This combination of an instrumental and a more ethical approach can be seen as part of an uneasy 'neoliberal-liberal interface' which can be highly problematic, part of a 'moderncolonial grammar that emphasizes self-affirmation and individual choice and agency' (Pashby and Andreotti, 2016:12) over the pragmatism and open mindset required for a truly intercultural approach to development issues. Too much emphasis on professional skills can lead some students into a highly instrumental approach which undervalues the intercultural and ethical elements of the placement experience. This was evident, for example, in one student's disappointment that what had otherwise been a very successful placement had not equipped them with the exact employability skills they expected to gain:

I feel that prospective employers would prefer skills directed to a specific job role. I did wish to gain skills in team leading, working with younger people and other areas aimed to roles I may wish to be employed in, however I haven't been allowed this opportunity by the company, which has been frustrating. (Student G, 2016).

A placement provider emphasized a similar dichotomy among student volunteers between those whose main emphasis was instrumental, and those who are predisposed through either beliefs or experience to place more value on taking ethical responsibility for 'other people's lives': 
I want to make sure they have the right attitudes, that they are communicative, that they can talk with people who are from different backgrounds ... Sometimes they will just honestly say I just want to do this because I want to get work experience to put on my $\mathrm{CV}$ to get a job later, which is fine if they're upfront at first, then we know it's probably a different kind of attitude to expect from this person than if they're saying ... my parents were refugees, or my grandfather was a refugee, or my neighbour is a refugee ... (Provider X, 2016).

There are echoes here of Bourdieu and Passeron's (1990) argument that education pursued instrumentally in a capitalist market environment (what Provider X described as the 'flashy brochure' approach to postgraduate study) can become a way of internalising the forms of cultural capital of the dominant group in society, therefore reproducing and entrenching existing inequalities - a particular irony for Development students who may otherwise be deeply committed to progressive change. These contradictions, while they cannot be avoided, can perhaps be confronted by placing a greater emphasis in the learning outcomes on the fostering of a "global-self" (Killick, 2017:57) which gives equal priority to affective capabilities (a sense of themselves in the world) and practical capabilities (knowledge and skills), and IaH provides a framework to support that ethical dimension. 


\section{Conclusions: Improving Skills and Opening Minds}

The PDP block of the MA in International Development demonstrates an attempt to bring together the principles associated with Internationalisation at Home - the use of an extended curriculum and cross-cultural learning embedded in experience and the building of new community relationships - with a focus on enhanced employability and professional engagement. Its "at home" nature makes it equally accessible (and challenging) to the whole cohort, regardless of students' origins, previous experiences or "cultural capital”. For domestic and international students alike, undertaking a "home" placement gives them a chance to move beyond the classroom study of international development, and to begin to apply that knowledge to real-world problems. Most important from a disciplinary perspective, however, it is also an opportunity to shed what can be seen as neo-colonial development ideals (described by Provider $\mathrm{X}$ as 'this idea of saving the world') by immersing them in an environment which requires a pragmatic ethics of openness, an ability to connect global actions and local consequences, and a readiness to challenge barriers and resistance between communities where they find them.

This survey of student and provider reflections is clearly small-scale, and would need to be scaled up to meet the universal requirements of $\mathrm{IaH}$ - a practical challenge which suggests important directions for future research into transferability, and the building of creative partnerships with external groups to facilitate the two-way exchange between students' knowledge and commitment, and the providers' professional expertise. However, the findings suggest that using IaH as a framework for enhancing employability has clear benefits in helping students to develop (and make connections between) their ability to apply their academic knowledge in a practical and culturally diverse setting, and their sense of 
being "prepared" for the demands of the professional world. The nature of these benefits suggests transferability to other disciplines, although the exact nature of the placement experience will vary; as Jones (2016:113) argues, 'the task of the academic is to identify the type of experience or activity which can facilitate intercultural learning in their specific discipline'. A third dimension of IaH - the building of relationships between students/the University and local community groups, and exposure to the ethical dimensions of professional practice - also lends itself particularly well to an "at home" placement, in spite of the sometimes tricky logistics of identifying a suitably "glocal” placement host. However, it is this dimension - 'a sense of responsibility, how everything is connected' (Provider X, 2016) - which students sometimes under-prioritize in their reflections, revealing certain tensions between discourses of employability and intercultural competence, and between improving skills and opening minds. IaH provides an opportunity to frame academic achievement and professional employability as implicitly connected to a capacity for understanding ethical responsibility; ensuring the latter is equally valued remains the challenge, but ultimately the measure of success of pathways like the PDP in supporting the development of truly 'global selves'. 


\section{References}

Barker, M. C. and Mak, A. S. (2013) From classroom to boardroom and ward: Developing generic intercultural skills in diverse disciplines. Journal of Studies in International Education, 17 (5), pp. 573-589.

Beelen, J. (2011) Internationalisation at Home in a Global Perspective: A Critical Survey of the $3^{\text {rd }}$ Global Survey Report of IAU. In: Globalisation and Internationalisation of Higher Education [online monograph]. Revista de Universidad y Sociedad del Conocimiento (RUSC). Vol. 8, No 2, pp. 249-264. UOC.

Beelen, J. and Jones, E. (2015) Redefining Internationalization at Home. In, A. Curaj et al (eds), The European Higher Education Area: Between Critical Reflections and Future Policies. Heidelberg: Springer. PP59-72.

Bourdieu, P. and Passeron, J-C. (1990) Reproduction in Education, Society and Culture. $2^{\text {nd }}$ ed. London: Sage.

Braskamp, L. A. (2009) Internationalizing a Campus: A Framework for Assessing Its Progress, Journal of College and Character, 10 (7), pp. 1-8.

British Council (2013) Culture at Work: the Value of Intercultural Skills in the Workplace. British Council.

Deardorff, D. K. (2006) Identification and Assessment of Intercultural Competence as a Student Outcome of Internationalization. Journal of Studies in International Education, 10 (3), pp. 241-266

De Wit, H. (2010) Internationalisation of Higher Education in Europe and its assessment, trends and issues. Amsterdam: NVAO. 
EP-NUFFIC (2014a) Management Summary: Internationalising Students in the Home

Country. Available from: https://www.epnuffic.nl/en/publications/find-a-

publication/management-summary-internationalising-students-in-the-home-country.pdf (accessed 17 June 2016).

EP-NUFFIC (2014b) Management Summary: Internationalising Students in the Home Country - Part II, In Practice. Available from:

https://www.epnuffic.nl/en/publications/find-a-publication/management-summaryinternationalising-students-in-the-home-country-part-2-in-practice.pdf (accessed 20 June 2016).

European Commission (2014) The Erasmus Impact Study: Effects of mobility on the skills and employability of students and the internationalisation of higher education institutions. Luxembourg: Publications Office of the European Union.

Gribble, C. (2015) IEAA International Employability Symposium: Outcomes Report 2015. Melbourne: IEAA.

Hammer, M.R. (2009) The Intercultural Development Inventory. In M.A. Moodian (Ed.). Contemporary Leadership and Intercultural Competence. Thousand Oaks, CA: Sage. PP 203-218.

Harrison, N. (2016) Global Citizens, Global Workers or Home Alone: Meeting the Challenges of Internationalisation at Home. Unpublished conference paper, IOC Internationalising the Curriculum Conference, Nottingham Trent University, 14 July 2016.

Higher Education Academy (2014) Internationalising the Curriculum. Available from: https://www.heacademy.ac.uk/sites/default/files/resources/internationalising the_curriculu $\underline{\text { m.pdf }}$ (accessed 17 June 2016). 
Jones, E. (2013) Internationalization and employability: the role of intercultural experiences in the development of transferrable skills, Public Money and Management, 33 (2), pp. 95104.

Jones, E. (2016) Mobility, Graduate Employability and Local Internationalisation, in E. Jones et al (eds.), Global and Local Internationalization. Rotterdam: Sense Publishers. Pp. 107116.

Killick, D. (2007) Internationalisation of the curriculum: cross-cultural capability and global perspectives. Assessment, Teaching \& Learning Journal Leeds Met, Number 2 (Summer), pp.35-40.

Killick, D. (2013) Global citizenship, sojourning students and campus communities. Teaching in Higher Education, 18 (7), pp. 721-735.

Killick, D. (2017) Internationalization and Diversity in Higher Education: Implications for Teaching, Learning and Assessment. London: Palgrave.

Knight, J. (2008) Internationalisation: key concepts and elements, in M. Gaebel et al (eds), Internationalisation of European Higher Education: an EUA/ACA Handbook. Berlin: RAABE Academic Publishers, pp. 1-24.

Lambert, J., and Usher, A. (2013) Internationalization and the Domestic Student Experience. Toronto: Higher Education Strategy Associates.

Nilsson, B. (2003) Internationalisation at Home from a Swedish Perspective: The Case of Malmö. Journal of Studies in International Education, Vol. 7 No. 1, pp. 27-40. 
Pashby, K. and Andreotti, V. (2016) Ethical internationalisation in higher education: interfaces with international development and sustainability. Environmental Education Research, 22 (6), pp. 771-787.

Ramburuth, P. and Welch, C. (2005) Educating the Global Manager, Journal of Teaching in International Business, 16 (3), pp. 5-27.

Schwartz, S. H. (2012) An Overview of the Schwartz Theory of Basic Values. Online Readings in Psychology and Culture, 2 (1). Available from: http://dx.doi.org/10.9707/2307-0919.1116 (accessed 2 August 2016).

Soria, K. M. and Troisi, J. (2014) Internationalization at Home Alternatives to Study Abroad: Implications for Students' Development of Global, International and Intercultural Competencies, Journal of Studies in International Education, 18 (3), pp. 261-280.

Spencer-Oatey, H. and Stadler, S. (2009) The Global People Competency Framework:

Competencies for Effective Intercultural Interaction. Coventry: Centre for Applied Linguistics, University of Warwick.

Think Global (2011) The Global Skills Gap: Preparing Young People for the New Global Economy. London: Think Global.

Van Gaalen, A. and Gielesen, R. (2014) Internationalizing Students in the Home Country Dutch Policies. International Higher Education. Number 78. Special issue 2014. Boston: The Boston College Center for International Higher Education. Available from: http://ejournals.bc.edu/ojs/index.php/ihe/article/viewFile/5801/5171

Van Gaalen, A. and Gielesen, R. (2016) Internationalisation at Home: Dutch higher education policies. In E. Jones et al (eds.), Global and Local Internationalization. Rotterdam: Sense Publishers. Pp 149-154. 
Wächter, B. (2003) An Introduction: Internationalisation at Home in Context. Journal of Studies in International Education vol. 7 no. 1 pp. 5-11. 